Originais recebidos em 28/02/2019. Aceito para publicação em 16/07/2019. Avaliado pelo sistema double blind peer review. Publicado conforme normas da ABNT.

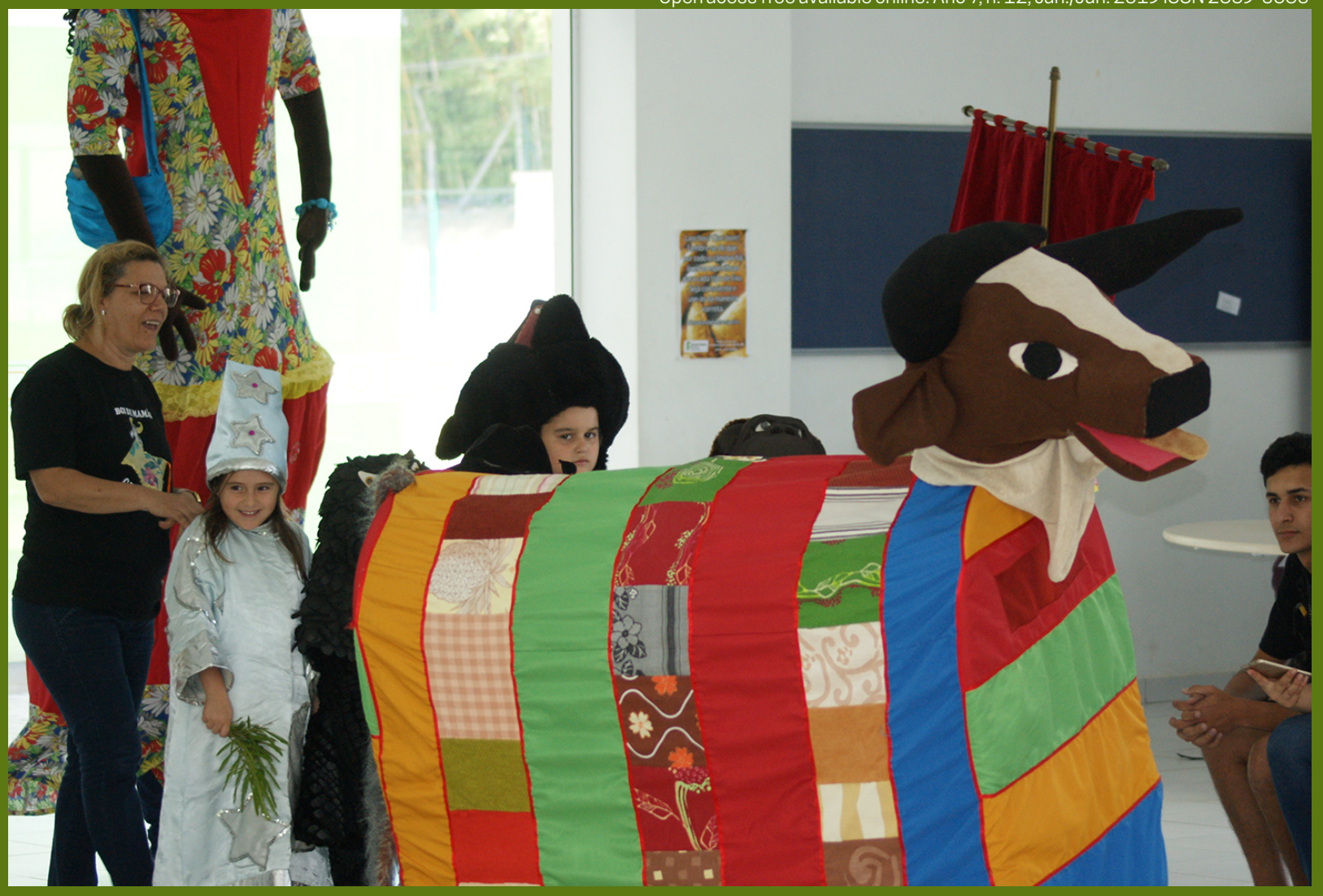

Mostra Curto-circuito de Arte e Cultura: Espaço de Formação, Experiência e Invenção

Jonathan Taveira Braga

jonathan.braga@ifsc.edu.br ${ }^{1}$

\title{
Gilberto Tonetto
}

gilberto.tonetto@ifsc.edu.br ${ }^{2}$

1 Formado em Educação Artística - Licenciatura em Artes Plásticas (UFPR/ 2010), mestre em Educação (UNESP/ 2014) e docente do IFSC/ Câmpus Criciúma.

2 Docente de Geografia no IFSC/ Câmpus Criciúma. 
A Mostra Curto-circuito de Arte e Cultura vem sendo desenvolvida desde 2016 no IFSC-Criciúma, visando à promoção de um circuito artístico de produção estudantil e profissional através da organização de mostras em diferentes linguagens. A ação também é vista como um processo de formação, envolvendo a comunidade interna e externa e tendo como protagonismo os alunos bolsistas na produção, desenvolvimento e conclusão do evento resultante.

Palavras-chave: Evento. Arte. Formação. Experiência.

ABSTRACT

The "Mostra Curto-circuito de Arte e Cultura" has been developed since 2016 at IFSC-Criciúma, aiming at the promotion of an artistic circuit of student and professional production through the organization of exhibitions in different languages. The action is also seen as a formation process, involving the internal and external community and having as protagonism the scholarship students in the production, development and conclusion of the resulting event.

Keywords: Event. Art. Formation. Experience.

\section{Relato de experiência}

A ação de extensão Mostra Curto-circuito de Arte e Cultura vem sendo desenvolvida desde 2016 no IFSC-Câmpus Criciúma, tendo sido concluídas até o momento quatro edições com pretensão de continuidade (1a edição, PJ009-2016; 2a edição, EV187-2017; 3a edição, EV014-2018; e a 4a edição, EV009-2019). Fomentada pelos editais PROEX-Didascálico, a ação possui como objetivo principal a promoção de um circuito artístico de produção estudantil e profissional, através da organização de mostras envolvendo as linguagens das Artes Visuais, do Teatro, da Dança, da Música, do Audiovisual, da Literatura e a proposição de Oficinas, pretendendo um dia inteiro de apresentações, exposições e interações culturais. Ainda, o fortalecimento da relação indissociável do ensino, da pesquisa e da extensão em atividades artístico-culturais, sendo um evento de caráter integrador e estratégico para as políticas de permanência e êxito.

Nesses quatro anos de realização, muita história se desenrolou no palco e espaços do nosso câmpus, envolvendo gradativamente a comunidade interna e externa para a vivência artística, troca de experiências e partilha de talentos. Nos momentos iniciais do projeto, ainda no campo das ideias, o esforço resumiuse na construção de um nome que representasse esse levante cultural - ação rápida e efêmera, capaz de aproximar produções artísticas internas e externas, amadoras e profissionais em um ambiente de interação, criatividade e sociabilidade. Partindo do princípio e da necessidade identificada junto à comunidade de inventar um circuito estudantil de exposição artística, encontramos no termo "curto-circuito" a possibilidade de dialogar com o caráter efêmero da ação, relacionando-a com a perspectiva de se criar um momento em que a ordem usual dos ambientes da instituição fosse reconfigurada pela lógica dos espaços e tempos próprios da experiência estética.

Ao compreender a experiência estética como produtora de sentidos sensíveis (DUARTEJUNIOR, 2001) pressupomos a arte como um elemento educativo e formativo, intencionalidade esta que provê elementos de apreensão das coisas do mundo como atividade significadora de ampliação de conhecimentos a regiões que o simbolismo conceitual não alcança (DUARTE JUNIOR, 1988, p. 16-17). Espaço de relação, atenção e invenção:

\footnotetext{
"a arte não transmite significados, mas exprime sentidos. Sentidos não conceituáveis e irredutíveis a palavras. A arte abre-me um campo de sentido por onde vagueiam os meus sentimentos, encontrando ali novas e múltiplas maneiras de ser" (DUARTE JUNIOR, 1988, p. 93).
}

Na perspectiva da experiência estética, a ação de extensão que viemos propondo e construindo traz, portanto, a possibilidade de ser vista também como estratégia de formação e subjetivação em espaços educativos formais ou informais. Espaços estes inseparáveis da sua dimensão expressiva e linguística que antes de "querer o mundo", pretende-se "dar sentido ao mundo", expandindo suas fronteiras na abrangência de sons, gestos e imagens. 
Enquanto espaço de formação, a Mostra requer o envolvimento intenso dos alunos extensionistas, bem como dos servidores, tanto na fase de pré-produção como pós-produção do evento. Seja mapeamento e contactando artistas, grupos e outras instituições sociais e de ensino para averiguação de disponibilidade e interesse nas exposições; seja fomentando a participação interna dos discentes e servidores do IFSC através de ações de divulgação dos regulamentos e inscrições, acompanhamento de ensaios e orientação de produções. A partir daquele mapeamento são encaminhados individualmente convites para as diferentes mostras do evento - Circuito Visual, Cênico, Musical, Literário, Cine-circuito e Oficinas Multiculturais -; produção de ilustração para cartazes de divulgação do evento, organização de materiais necessários, orçamentos de aluguel de equipamentos de iluminação, som e painéis móveis; confecção de camisetas, logos e plataformas digitais de inscrição; fechamento da programação do evento, recebimento das obras e montagem das exposições; apresentação e registro das atrações no palco, acompanhamento da comunidade externa no dia da ação, além da preparação e monitoria nas oficinas propostas. A intensidade das atividades realizadas pelos alunos extensionistas, sejam eles bolsistas ou voluntários, demonstram o protagonismo de suas ações para a concretização de um evento de porte médio dentro da instituição, resultando nessas quatro últimas edições no acolhimento de aproximadamente 180 atrações abrangendo as diferentes linguagens descritas.

Para a formatação e desenvolvimento da ação de extensão a equipe executora contou também com a participação direta da comunidade externa. Em contato com a Secretaria de Educação do Município de Criciúma, duas professoras, parceiras da instituição, indicaram as escolas que teriam interesse em apresentar suas produções no evento, o que estreitou os laços com tais escolas até os dias atuais. Essas instituições, além de apresentarem trabalhos nas diferentes edições da Mostra, passaram a conhecer o IFSC através de visitas guiadas organizadas em vários momentos durante o ano letivo, efetivando parcerias em outros projetos de extensão. Inclusive muitos dos alunos que participaram dessas ações tornaram-se alunos da nossa instituição em anos sequentes. Dessa forma acredita-se que o evento contribua com a missão de promover a inclusão e formar cidadãos, por meio da educação profissional, científica e tecnológica, gerando, difundindo e aplicando conhecimento e inovação, contribuindo para o desenvolvimento socioeconômico e cultural.

A esses propositores externos à Instituição, os quais estiveram no evento apresentando trabalhos e compondo o público-alvo de espectadores, a Mostra constitui uma oportunidade de tornar público um processo criativo e reflexivo, partilha de pesquisas, estímulo e divulgação artística, abertura e apropriação dos espaços do câmpus por diferentes instituições de ensino e artistas locais. Nos espaços do câmpus tivemos o privilégio de receber trabalhos profissionais de inquestionável qualidade e importância cultural local. Pelo evento passaram expressões da cultura popular, como por exemplo o Grupo de Boi de Mamão da Escola Municipal Natureza, o Grupo de Canto e Dança Polono-Brasileiro "Korzenie", o espetáculo "Homens da terra" do Coral Municipal de lçara, oficina de Cultura Material Indígena, dentre outras proposições externas, como companhias de teatro, balé e dança contemporânea, orquestras, artistas plásticos, ilustradores, cineastas e escritores da cidade e região.

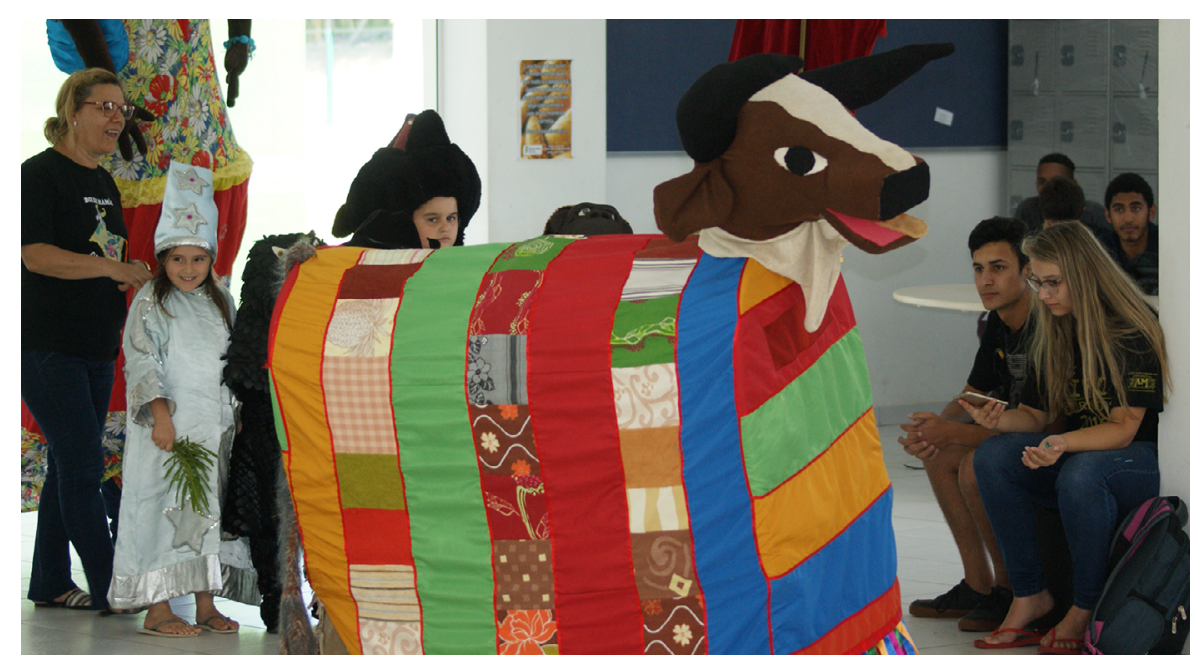

Figura 1: Apresentação na 1ạ edição da Mostra do Boi de Mamão da Escola Municipal Natureza (Novembro de 2016).

Fonte: Setor de Comunicação do IFSC/ Criciúma. 


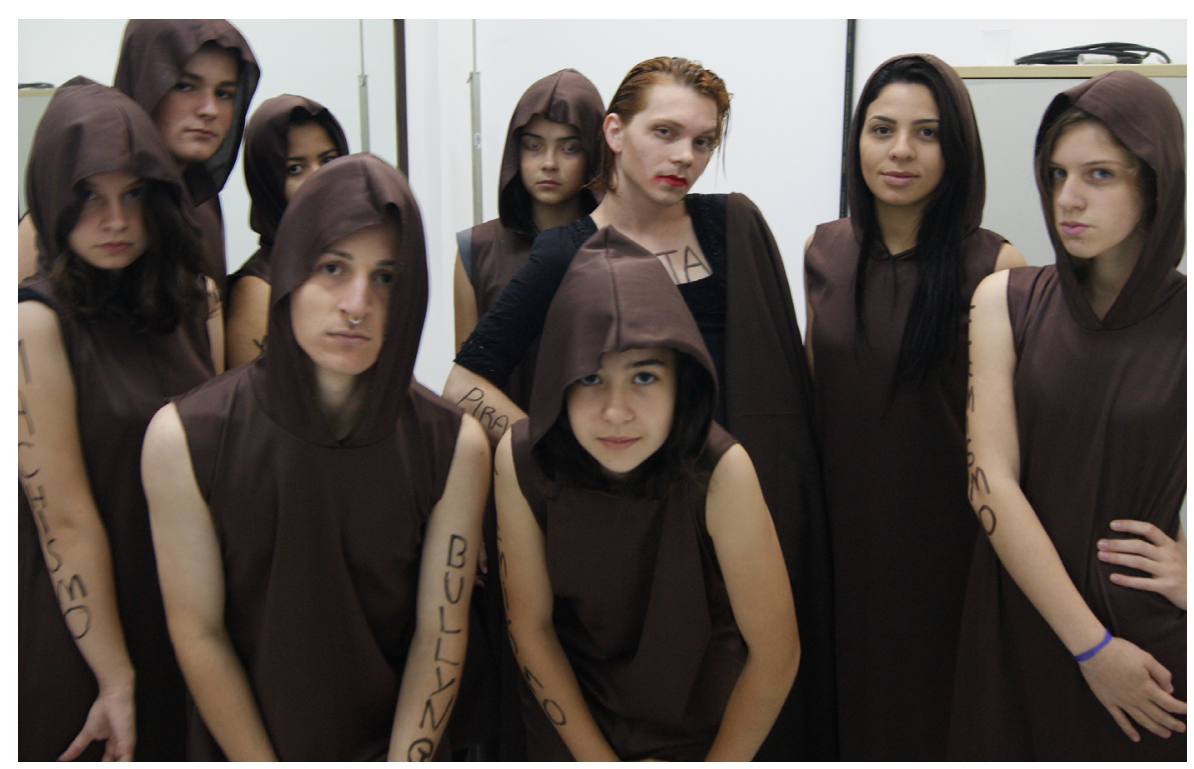

Figura 2: Apresentação de performance do Grupo de Teatro Urussanga Encena na 1a edição da Mostra (Novembro de 2016).

Fonte: Setor de Comunicação do IFSC/ Criciúma.

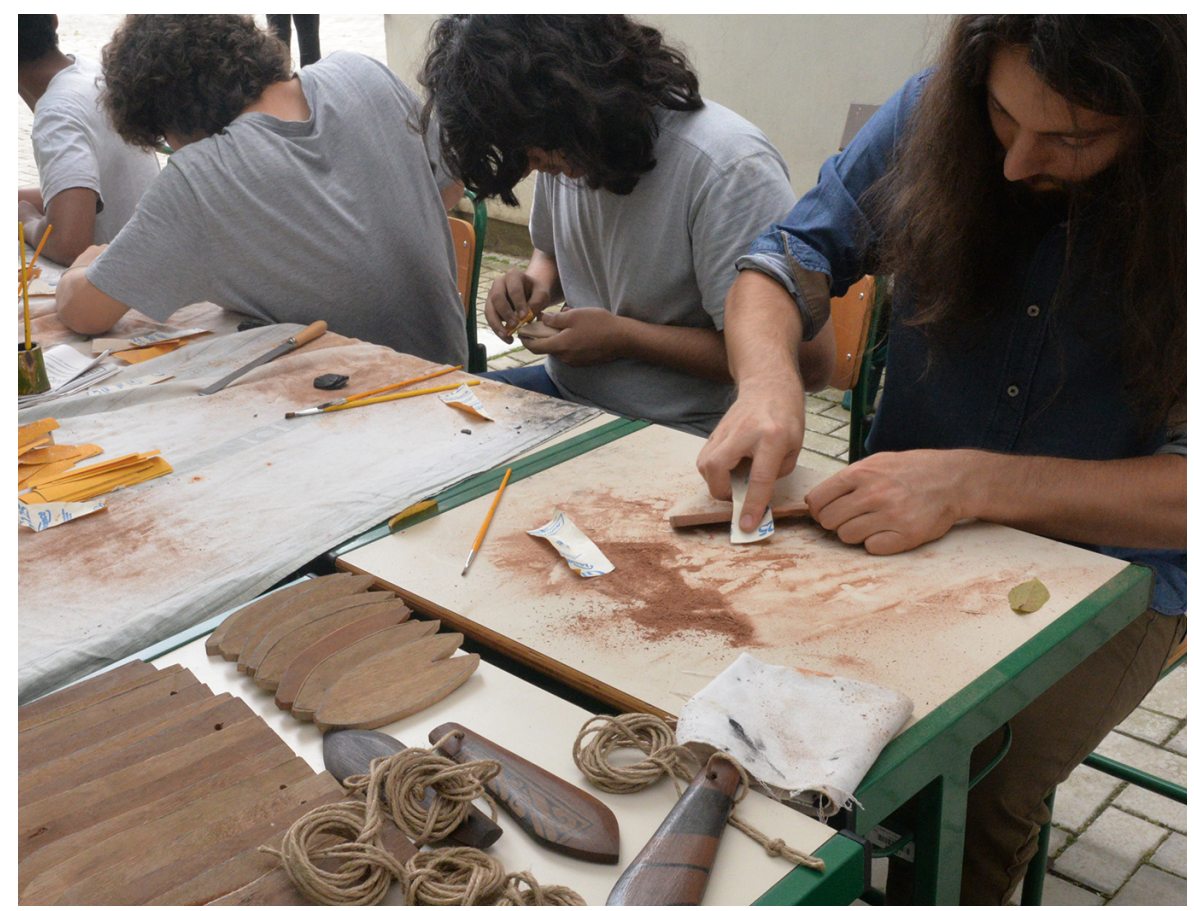

Figura 3: Registro da oficina Cultura Material Indígena, ministrada pelo artesão local Wilian Marques na $2^{a}$ edição da Mostra (Novembro de 2017).

Fonte: Setor de Comunicação do IFSC/ Criciúma. 


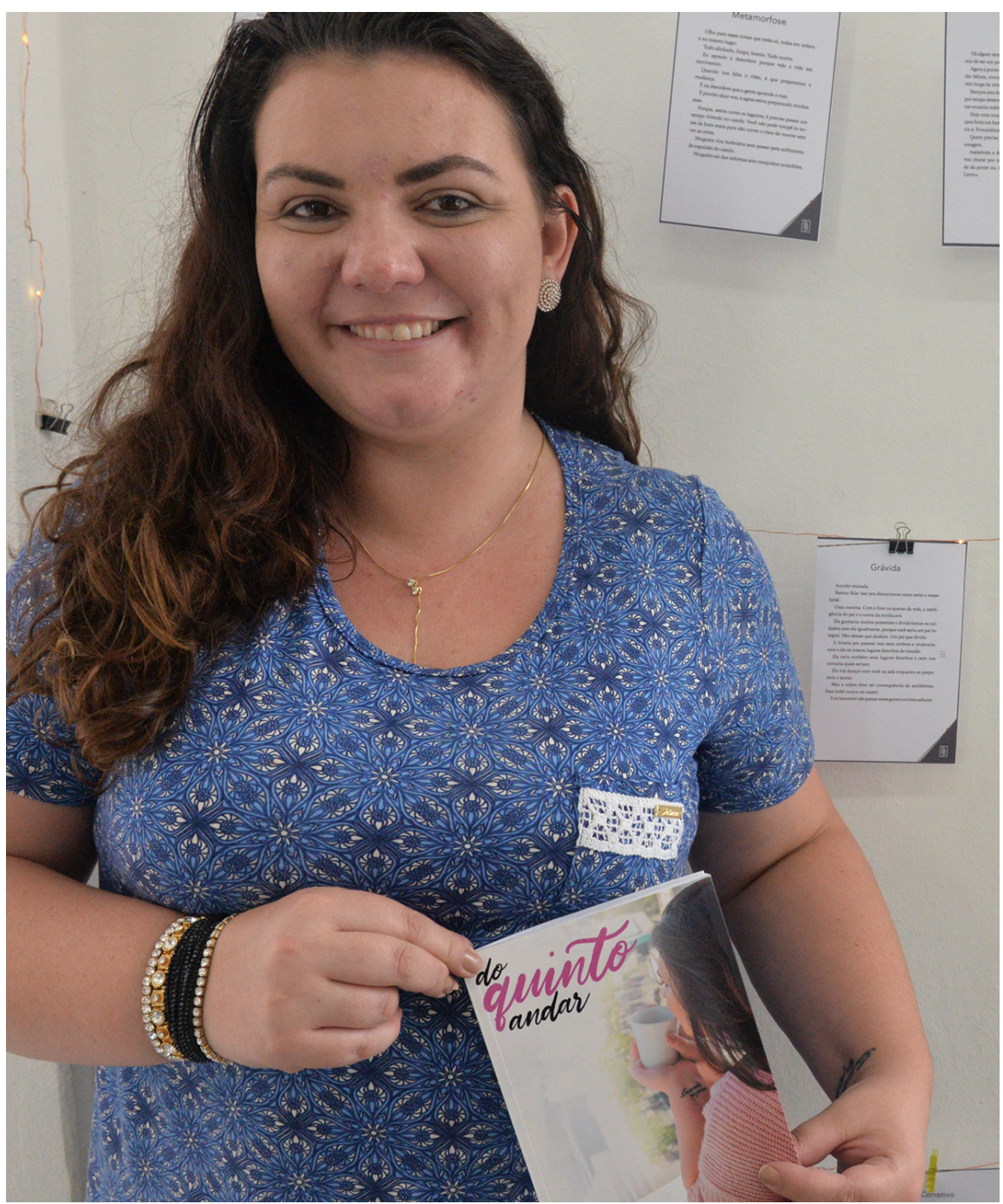

Figura 4: Lançamento de livro "Do quinto andar", da escritora Deise Duarte, na 2a edição da Mostra (Novembro de 2017)

Fonte: Setor de Comunicação do IFSC/ Criciúma.

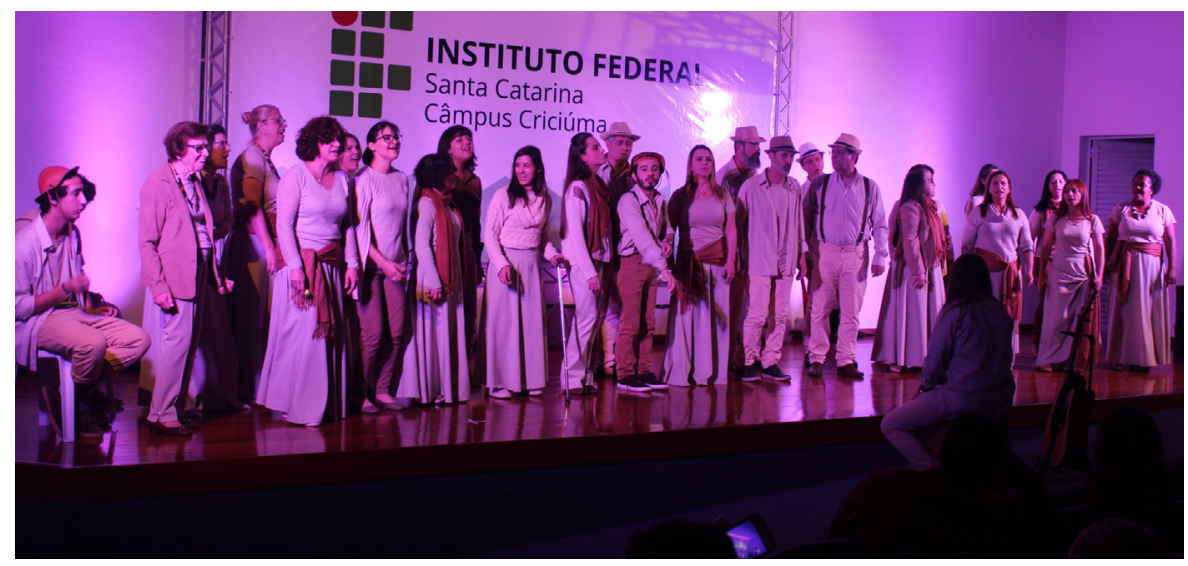

Figura 5: Apresentação do espetáculo "Homens da terra" do Coral Municipal de Içara, com regência de Reinaldo Hoepers, na 3a edição da Mostra (Setembro de 2018). Fonte: Setor de Comunicação do IFSC/ Criciúma. 


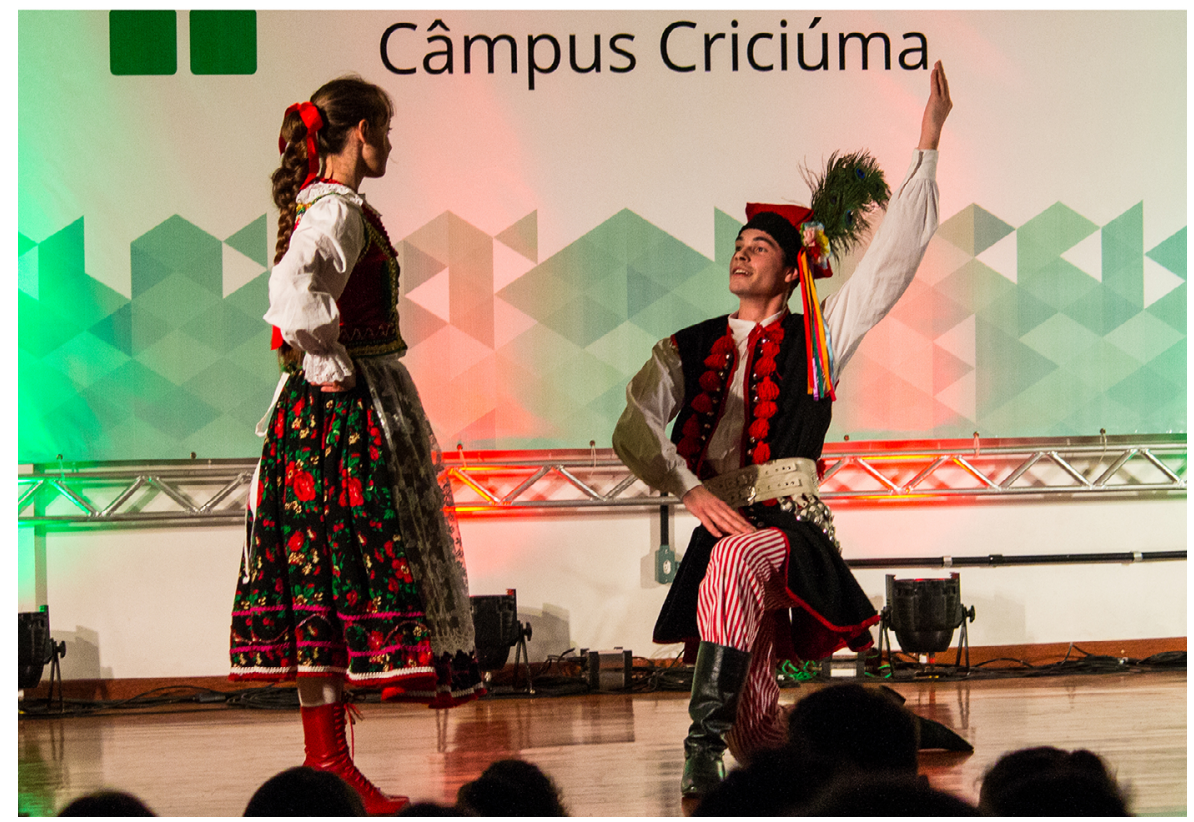

Figura 6: Apresentação do Grupo de Canto e Dança Polono-brasileiro "Korzenie" na 3ạ edição da Mostra (Setembro de 2018).

Fonte: Setor de Comunicação do IFSC/ Criciúma.

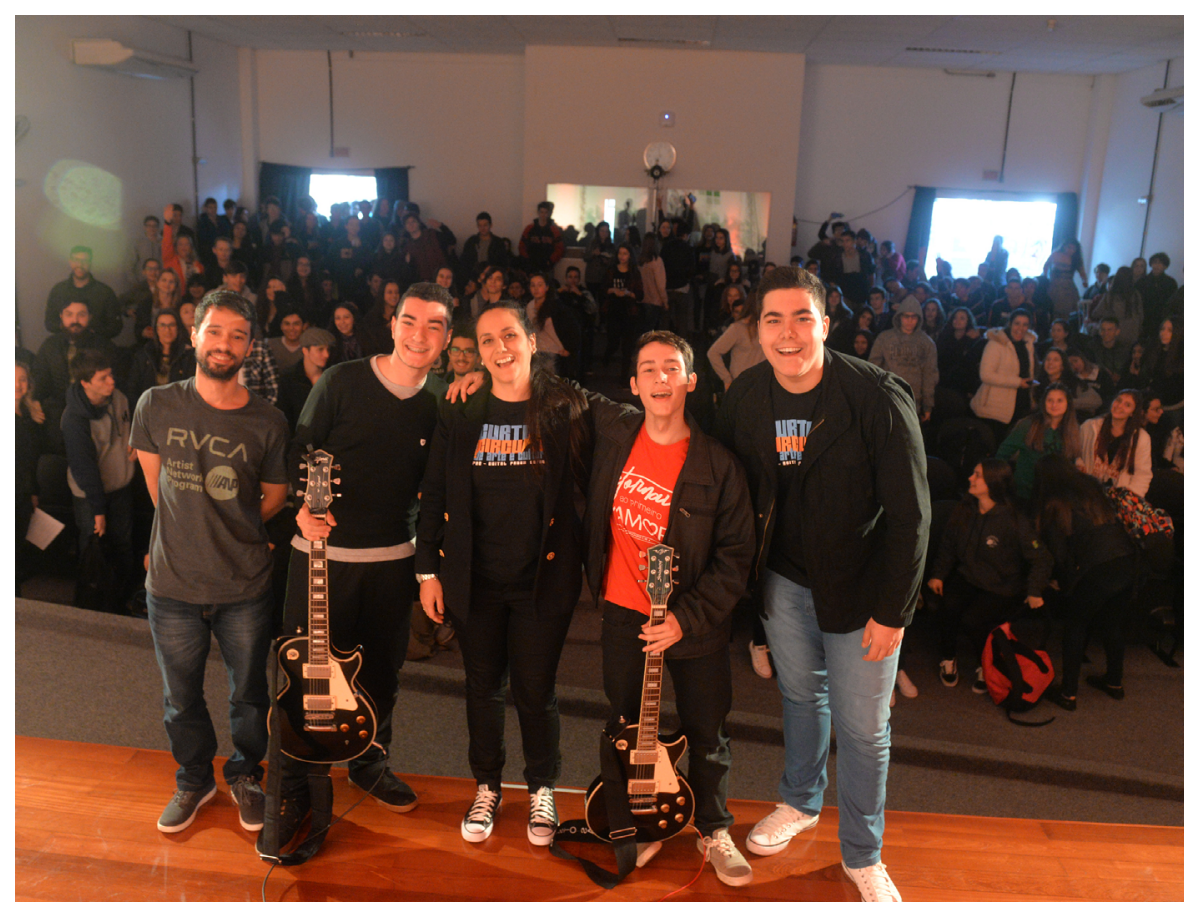

Figura 7: Apresentação de grupo musical formado por alunos e professores na 3ạ edição da Mostra (Setembro de 2018).

Fonte: Setor de Comunicação do IFSC/ Criciúma. 
Para além da participação da comunidade externa nas diferentes mostras do evento, através desta ação podemos também conhecer as diferentes habilidades do nosso corpo discente. Alunos e alunas, que muitas vezes encontravam-se silenciados em meio à rotina da instituição, encontraram na mostra a oportunidade de apresentar suas composições musicais, escritos poéticos em saraus e varais literários, esquetes teatrais, performances, coreografias, ilustrações, pinturas, desenhos e objetos. Trabalhos que sintetizam diferentes processos de subjetivação frente aos afetos capturados nas distintas existências e desafios contemporâneos. Pequenas e curtas amostras de desejos e anseios que configuram modos e maneiras de estar jovem num mundo de poucas certezas e grandes transformações.

Os registros ao longo dos quatro anos de evento resultaram em um acervo de imagens que proporcionaram a construção de catálogos que serviram para marcar de forma ilustrativa o evento na memória dos participantes e expositores. A cada edição um novo material gráfico é criado e produzido como forma de certificação aos artistas/ propositores. Como forma de reconhecer e enaltecer a participação da comunidade externa, principalmente as escolas, entregamos em formato digital o catálogo e enviamos os registros aos participantes. Destaca-se que no ano 2016 foi possível entregar a todas as escolas o catálogo impresso, fato que impactou de maneira positiva as instituições, chegando a ficar exposto nos murais de uma escola. Ainda a entrega dos catálogos, segundo os diretores, serve de estímulo a participação de outros grupos existentes na escola.

A rotina do campus nas semanas que antecederam tais edições do evento era de presença constante de instrumentos musicais e ensaios ao ar livre, fomentando outras relações com os espaços e com as pessoas que neles atravessavam. Aos alunos e participantes das ações do evento, a Mostra oportuniza o desenvolvimento de habilidades intra e interpessoais através da apreciação, vivência e publicação artística, contribuindo assim com a dimensão ética-estética das suas respectivas formações técnicas, profissionais e cidadãs ao ampliar seus repertórios culturais, linguísticos e possibilidades de ação.

\section{Referências}

JÚNIOR, J-F. D. Fundamentos estéticos da educação. 2.ed. Campinas: Papirus, 1988.

JÚNIOR, J-F. D. 0 sentido dos sentidos: a educação (do) sensível. Curitiba: Criar, 2001. 